\title{
Erratum to: Mitochondrial pathways are involved in Eimeria tenella-induced apoptosis of chick embryo cecal epithelial cells
}

\author{
Shan $\mathrm{Li}^{1} \cdot$ Ming-xue Zheng ${ }^{1} \cdot$ Huan-cheng $\mathrm{Xu}^{1} \cdot \mathrm{Xian}^{1}$-zhen $\mathrm{Cui}^{1} \cdot$ Yan Zhang ${ }^{1}$ • \\ Li Zhang ${ }^{1} \cdot$ Sha-sha Yang ${ }^{1} \cdot$ Zhi-yong Xu $^{1} \cdot$ Rui Bai $^{1} \cdot$ Xu-guang Sun ${ }^{1}$
}

Published online: 27 January 2017

(C) Springer-Verlag Berlin Heidelberg 2017

Erratum to: Parasitology Research

DOI 10.1007/s00436-016-5283-Z

Two photos in Figure 2a in the original version of this article were misplaced. The correct figure is presented below.

The online version of the original article can be found at 10.1007/s00436016-5283-z.

Ming-xue Zheng

zhengmingxue288@163.com

1 College of Animal Science and Technology, Shanxi Agricultural University, Taigu 030801, Shanxi Province, People's Republic of China 
a

E.tenella
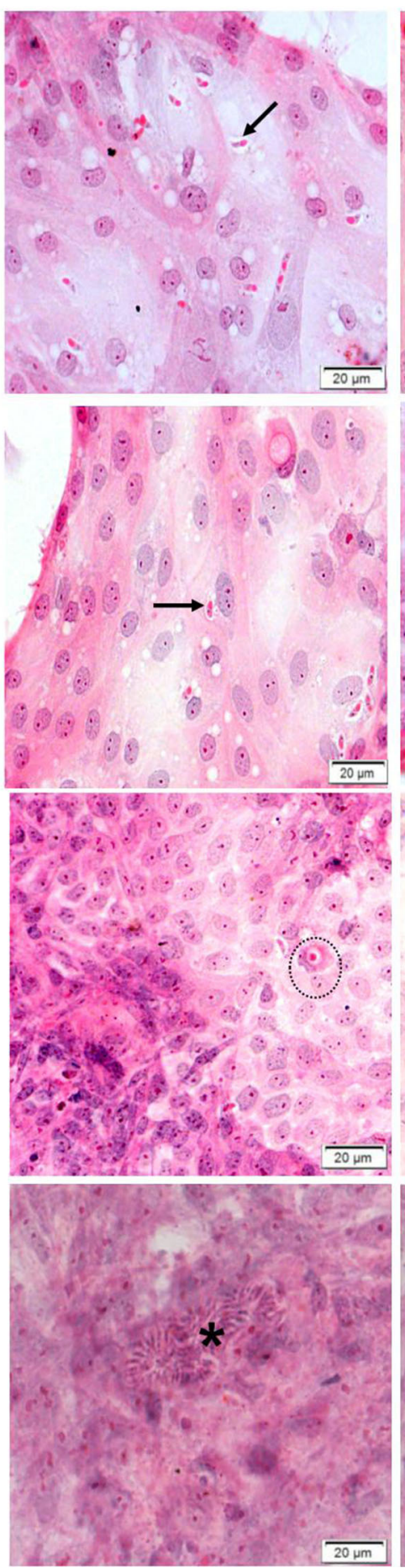

E.tenella +Z-LEHD-FMK
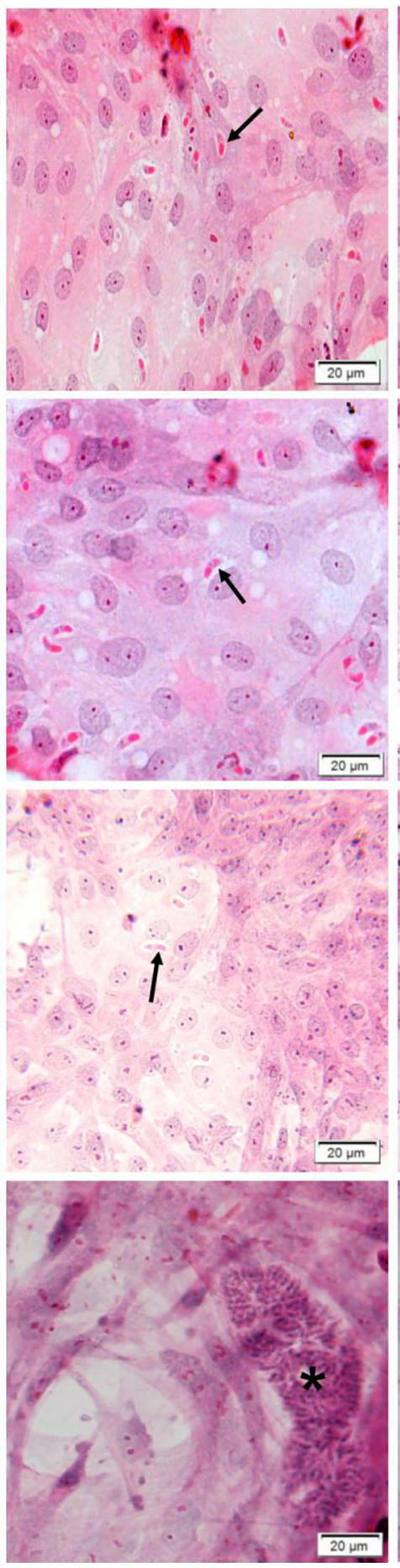

E.tenella $+\mathrm{CsA}$

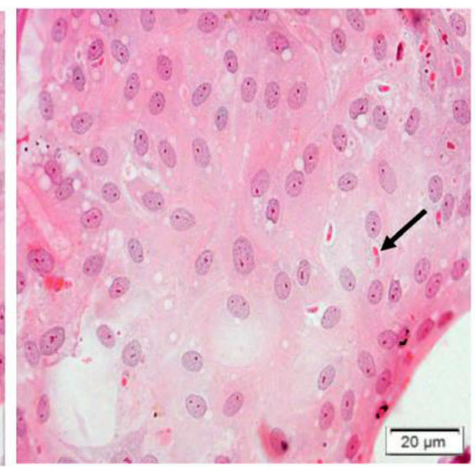

$4 \mathrm{~h}$

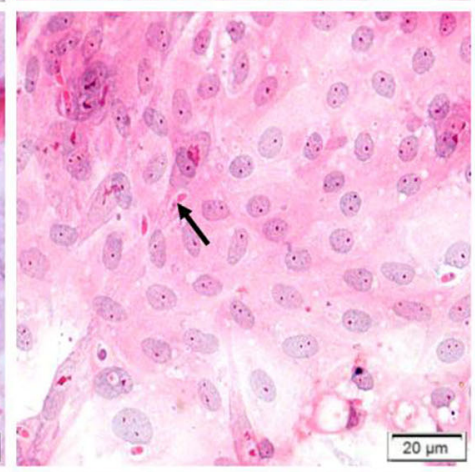

$24 \mathrm{~h}$

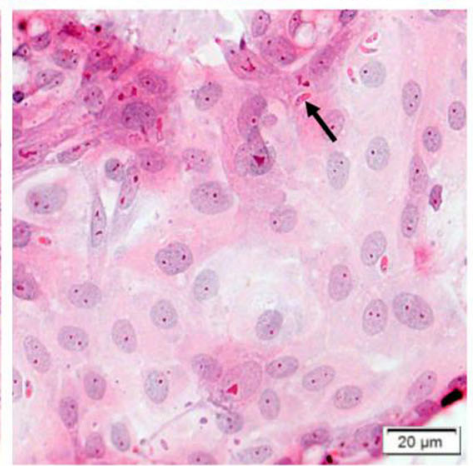

$48 \mathrm{~h}$

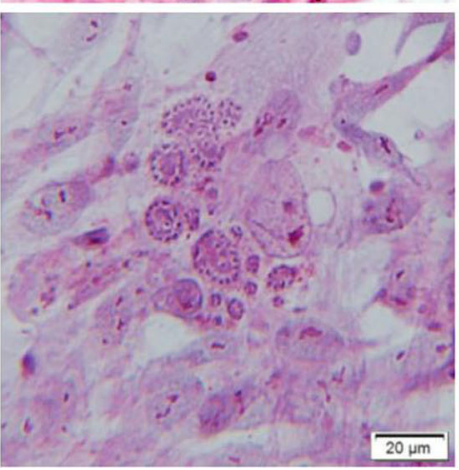

